\title{
Developing Social Accounting Matrix for Macedonia: a challenge ahead
}

\author{
Sasho Kjosev \\ University "Ss. Cyril and Methodius", Faculty of Economics, Skopje, Republic of \\ Macedonia \\ skosev@eccf.ukim.edu.mk \\ Blagica Novkovska \\ University of Tourism and Management, Faculty of Economics, Skopje, \\ Republic of Macedonia \\ b.novkovska@utms.edu.mk
}

\begin{abstract}
The Social Accounting Matrix (SAM), together with the SESAME approach, proved highly useful in providing the basis for in-depth analyses of all the socio-economic flows in the developed economies. The aim of this paper, after initial explanation of the theoretical foundations of these methods for the development analysis, is to contribute to raising the awareness of the urgent necessity for developing and implementing these methodological approaches in the Republic of Macedonia. Special attention is paid to the analysis of the current situation related to the readiness of the national statistical system to provide all the necessary statistical data and logistical support for a more efficient preparation and implementation of these methodological approaches in the national economy. The paper analyses in detail the data describing particularly important aspects of the position of workers on the labour market aimed to be used as a basis for the SESAME approach. A comparative analysis with reference to the EU countries has been performed. The paper concludes by presenting practical recommendations which should, in our opinion, lead to preparation and implementation of the SAM and its extension (SESAME) in the Republic of Macedonia. The named should be used for the successful decision-making process related to creation and implementation of efficient macroeconomic and development policies in the country.
\end{abstract}

Keywords: Macedonia, macroeconomic policies, SESAME, Social Accounting Matrix, sustainable development.

JEL classification: C54, C55, C82, O21.

DOI: 10.1515/crebss-2017-0006

Received: November 1, 2017

Accepted: December 22, 2017

Acknowledgments: We dedicate this paper to our families, for their continuous support and understanding. 


\section{Introduction}

Developing and implementing relevant methodology for a proper macroeconomic and development analysis is significantly important for the national economies' system of sustainable development. Its main goal is to provide adequate methodological basis for analysing development challenges of the national economies existing in the process of preparing ad implementing strategic and planning documents.

Having this in mind, we start by short presentation of the analytical basis of the Social Accounting Matrix and SESAME. Then, we proceed with Part 2 with the analysis of the current situation related to the level of readiness of the national statistical system to provide all the necessary statistical data and logistical support for a more efficient preparation and implementation of these methodological approaches in the national economy. At the end, the paper concludes by that can contribute to elaboration and practising well designed macroeconomic and development policies in the Republic of Macedonia.

\section{Literature review}

The first comprehensive approach in defining and developing Social Accounting Matrix methodology was undertaken by producing the World Bank publication "Social Accounting Matrices - a Basis for Planning" (Pyatt, Round (Eds.), 1985). The social accounting approach illustrated in this volume recorded particular attempts at meeting the practical need within the limitations of (a) currently available statistics, and (b) current perceptions as to the best way of assembling them. The main goal of this publication was to show how the macro data set, such as the Social Accounting Matrix, can be successfully used for the preparation of scientifically and research based macroeconomic analysis.

The institutional background of this approach was provided with the publication "System of National Accounts 1993" (European Commission et al., 1993), where SAM is presented as a comprehensive system, comprised of set of national accounts with a main goal to serve the needs of the relevant stakeholders in the macroeconomic policy decision making process.

Beyond this, a number of papers discuss and develops further the SAM concept. Based on the work of Keuning and Timmerman (1995) and Keuning $(1998,2000)$, the concept of SESAME was elaborated and implemented. SESAME goes beyond the SAM concept as it provides theoretical and practical linkages between monetary and non-monetary phenomena.

Finally, Kjosev and Novkovska (2017), Kjosev, Gockov and Eftimov (2014) and Kjosev (2012) and in their papers, are urgently proposing developing and implementation of the SAM and SESAME methodologies and approaches for creation of effective macroeconomic and development policy documents.

\section{Theoretical Background}

\section{Social Accounting Matrix}

Social accounting matrix (SAM) is a research and analytical technique related to national accounting, presenting a theoretical basis for analysing growth and distributional issues within a single analytical framework in an economy.

A SAM is defined as the presentation of System of National Accounts (SNA) accounts in a matrix which elaborates the linkages between a supply and use table and institutional sector accounts. (European Commission et al., 1993) 
Below we list the features of the SAM are identified to be the most important:

First, it efficiently contributes to combining growth indicators, income allocation and poverty in one consistent framework;

Second, SAM is a preferred means for adjusting various data sources and bridging the gap in information received from various statistical sources of data;

Third, SAM is useful integrated statistical database for preparation and implementation of macroeconomic models, thus contributing to more efficient analytically based decision making process in the national economies (Kjosev, 2012).

\section{SESAME (System of Economic and Social Accounting matrices and Extensions) approach}

SESAME (System of Economic and Social Accounting matrices and Extensions) is a statistical information system in matrix format, from which a set of core socioeconomic and environmental macro-indicators is derived (Keuning, 1998).

In his paper, Keuning (2000) points out to the advantages of the SESAME approach. It is affirmed that SESAME provides core macroeconomic indicators and adequate statistical information system. In addition, it promotes the use of harmonized statistical procedures, classifications and concepts, thus contributing to easier adjustment and harmonization of the data from different sources of data. Besides, SESAME is an inherently flexible framework, which can be efficiently adjusted to the specific requirements of a national economy or a region. Finally, the basic goal of the SESAME is to enable more efficient use of statistics from the existing statistical data sources.

Construction of SAM/SESAME for various macroeconomic variables is a complex task which will require extensive research activities. In this work we present an initial analysis of particular characteristics of the labour market highly relevant for the unemployment rate, with is the most sensitive issue for Macedonian economy.

\section{Research methodology}

Realization of the goal of expected set of studies aimed at establishing functional Social Accounting Matrix for Macedonia requires exhaustive investigation of several important issues. In this work we put emphasize on the SESAME approach, particularly on the structure of the labour market and the most severe issue for the Macedonian economy - the high unemployment rate. Most important figures describing the labour market are used in the analyses.

Data for the size of total population and distribution by age groups, data for the share of employees with a contract of limited duration for the working age population (15 to 64), data for the share of employees with a contract of limited duration for young population (15 to 24), and data for full-time employment by economic activity are used in the analyses. Values reported in Eurostat data base and in documents of State Statistical Office of Republic of Macedonia for the period 2012-2016 have been used on complementary basis in the work. Thus, the most recent comprehensive set of data required for analysis is obtained. The period five years is considered to be enough long to identify the main trend in the analysed characteristics of the labour market.

Comparative analysis of the data for different subcategories has been the main method used in this work.

The main research hypothesis for this work is that the application of the methods for construction of Social Accounting Matrix for Macedonia will provide tools for indeep analysis of the socio-economic circumstances, assist in identifying the issues 
that require particular attention. Policies to be adopted for alleviation of the most severe problems can be constructed based on these findings.

\section{Results and discussion}

\section{Recommendations to be made for Republic of Macedonia}

At this stage of socio-economic development and confronted with the bitter socioeconomic reality, what Republic of Macedonia needs is building an efficient macroeconomic and sustainable development planning system.

This new system would have to be comprised of the following most important elements: a highly disaggregated Social Accounting Matrix (SAM), and ASAM extended with social indicators (SESAME approach).

\section{SAM in the case of Republic of Macedonia}

Having in mind the discouraging fact that there is no Social Accounting Matrix (SAM) for the Republic of Macedonia, it is our professional and expert opinion that there is a pressing need for the State Statistical Office, together with the relevant Government institutions, to start building and utilizing a Social Accounting Matrix methodology in the Republic of Macedonia.

Here, one should have in mind and try to implement the activities listed below:

First, building, adjusting and utilizing integrated statistical framework which will be used as a significant methodological and analytical basis in the sustainable development planning and policy creation and implementation process;

Second activity is expected to be the building a SAM for the national economy, by using in this process the extensive experiences of the countries with functional market economies.

\section{SESAME in the case of Republic of Macedonia}

It is expected SESAME approach to provide high added value while using disaggregated representation of labour market, by distinguishing various categories of employed persons. Below is discussed the issue how to proceed in such a disaggregation and what are the expected benefits of such an approach.

First to be discussed is the issue of unemployment. Unemployment for Republic of Macedonia is a rather hard concern to cope with. Even in the previous system with command economy, where other similar countries had low unemployment rates, Republic of Macedonia exhibited rather high unemployment rates. After the economic transition to market economy, very high values of unemployment rate, up to about $40 \%$, were observed in certain periods. Thus, relevant data for various characteristics of the labour market are of crucial importance for socio-economic analyses. SESAME approach implementation in the Republic of Macedonia is to be based on these figures.

Second, the pressure of the high unemployment rate results in a particular structure of the labour market, manifested by strongly perturbed percentage of fulltime employments and number of work contracts of limited duration. This issue will be discussed below in order to demonstrate the efficiency of a method using SESAME approach.

Below are shown and discussed data on labour market, organized generally as it was proposed in the work (Kjosev, 2012). Five-year period (2012-2016) was considered in order to obtain sufficiently long period (medium term) for following temporal variations. In the systematic use of the SESAME approach much longer time series are expected to be obtained for more detailed analyses. 
First, in Table 1 the evolution of the size of total population and distribution by age groups, both as absolute values (number of inhabitants) and percentages are shown for the period 2012-2016. Aging of the population is notably visible; percentage of the age group 65+ increased from $11.90 \%$ in 2012 to $13.12 \%$ in 2016, while percentage of the age group $0-14$ decreased $17.10 \%$ to $16.60 \%$ during the same period.

Table 1 Population estimations for Republic of Macedonia, 30.06., by age groups

\begin{tabular}{|l|r|r|r|r|r|}
\hline geo\time & \multicolumn{1}{|c|}{2012} & \multicolumn{1}{|c|}{2013} & \multicolumn{1}{|c|}{2014} & \multicolumn{1}{|c|}{2015} & \multicolumn{1}{c|}{2016} \\
\hline \multicolumn{7}{|c|}{ Number } \\
\hline Total & $2,061,044$ & $2,064,032$ & $2,067,471$ & $2,070,226$ & $2,072,490$ \\
$15-64$ & 352,442 & 349,783 & 348,033 & 346,273 & 344,110 \\
$65+$ & $1,462,995$ & $1,462,445$ & $1,460,355$ & $1,458,089$ & $1,456,146$ \\
Unknown & 245,195 & 251,430 & 258,749 & 265,570 & 271,986 \\
\hline \multicolumn{7}{|c|}{ Structure } \\
\hline Total & 412 & 374 & 294 & 248 \\
0-14 & 100.00 & 100.00 & 100.00 & 100.00 & 100.00 \\
$15-64$ & 17.10 & 16.95 & 16.83 & 16.73 & 16.60 \\
65+ & 70.98 & 70.85 & 70.63 & 70.43 & 70.26 \\
Unknown & 11.90 & 12.18 & 12.52 & 12.83 & 13.12 \\
Unkny & 0.02 & 0.02 & 0.02 & 0.01 & 0.01 \\
\hline
\end{tabular}

Source: State Statistical Office, 2017.

Table 2 Employees with a contract of limited duration (annual average), \% of total number of employees, from 15 to 64 years

\begin{tabular}{|l|r|r|r|r|r|}
\hline \multicolumn{1}{|c|}{ geo\time } & \multicolumn{1}{c|}{2012} & \multicolumn{1}{c|}{2013} & \multicolumn{1}{c|}{2014} & \multicolumn{1}{c|}{2015} & \multicolumn{1}{c|}{2016} \\
\hline EU (28 countries) & 11.5 & 11.5 & 11.7 & 11.9 & 12.0 \\
EU (27 countries) & 11.5 & 11.5 & 11.7 & 11.9 & 12.0 \\
Republic of Macedonia & 10.6 & 11.0 & 11.4 & 9.4 & 10.4 \\
Bulgaria & 3.9 & 4.9 & 4.6 & 3.9 & 3.6 \\
Estonia & 3.2 & 3.2 & 2.8 & 3.1 & 3.4 \\
Latvia & 4.2 & 3.8 & 2.9 & 3.3 & 3.2 \\
Lithuania & 2.3 & 2.4 & 2.4 & 1.8 & 1.7 \\
Romania & 1.1 & 1.0 & 1.1 & 1.0 & 1.0 \\
Spain & 19.5 & 19.1 & 19.9 & 20.9 & 21.8 \\
Croatia & 10.9 & 12.1 & 14.4 & 17.2 & 19.3 \\
Poland & 16.2 & 17.0 & 17.7 & 16.7 & 17.2 \\
Portugal & 20.9 & 21.1 & 22.4 & 22.2 & 21.9 \\
Slovenia & 16.9 & 17.6 & 18.0 & 18.7 & 19.1 \\
\hline
\end{tabular}

Source: Eurostat, 2017, State Statistical Office, 2017.

In Table 2 the evolution of the percentage of employees with a contract of limited duration (annual average) is shown for the period 2012-2016, in comparison with EU averages and values for two groups of EU countries - five countries with highest percentages and five other countries with lowest percentages. It is seen that this percentage for Macedonia is relatively stable (varies between $11.5 \%$ and $12.0 \%$ ). This value is close to the EU-28 average, which could be erroneously interpreted as an indicator that the labour market in Macedonia has characteristics of a typical EU economy. In-deep analysis given below shows that there are peculiarities, that do not exist in any other of the considered countries. Thus, in comparison with more developed countries (such as Slovenia, Portugal and Spain), this value is low, but when comparing to Bulgaria (3.6\% in 2016) and Romania (1.0\%), it is rather high. Small variations of percentages are observed for other countries except Croatia. For 
Croatia, a country that recently accessed the EU, at the beginning of the considered period the percentage was relatively low (10.9\% in 2012), while at the end of the period it attained a value close to the percentages for Slovenia, Portugal and Spain (19.3\% in 2016). Above transition from medium to high percentages can be attributed to the changes immediately before and after the accession to EU. Therefore, it is to be concluded that in Macedonia position of the workers on the labour market is substantially more insecure than in the countries with similar level of economic development.

Table 3 Employees with a contract of limited duration (annual average), \% of total number of employees, from 15 to 24 years

\begin{tabular}{|l|r|r|r|r|r|}
\hline \multicolumn{1}{|c|}{ geo } & \multicolumn{1}{c|}{2012 time } & \multicolumn{1}{c|}{2013} & \multicolumn{1}{c|}{2014} & \multicolumn{1}{c|}{2015} & \multicolumn{1}{c|}{2016} \\
\hline EU (28 countries) & 39.0 & 39.3 & 40.1 & 40.3 & 40.8 \\
EU (27 countries) & 39.0 & 39.3 & 40.1 & 40.3 & 40.7 \\
Republic of Macedonia & 22.2 & 25.8 & 26.2 & 23.5 & 22.2 \\
Bulgaria & 9.0 & 12.4 & 13.6 & 11.1 & 12.7 \\
Estonia & 12.6 & 11.9 & 11.0 & 11.2 & 12.6 \\
Latvia & 9.3 & 9.4 & 7.8 & 10.1 & 7.7 \\
Lithuania & $8.9(U)$ & $7.6(U)$ & 7.9 & $6.1(U)$ & $7.2(U)$ \\
Romania & 3.0 & 3.4 & 3.8 & 3.0 & 3.0 \\
Spain & 56.8 & 58.4 & 62.5 & 64.5 & 67.7 \\
Croatia & 41.8 & 40.3 & 53.1 & 57.3 & 61.7 \\
Poland & 57.5 & 59.7 & 63.2 & 64.4 & 62.5 \\
Portugal & 52.6 & 56.6 & 59.0 & 63.9 & 62.8 \\
Slovenia & 60.7 & 58.5 & 57.2 & 62.7 & 66.3 \\
\hline
\end{tabular}

Note: $u=$ low reliability.

Source: Eurostat, 2017, State Statistical Office, 2017.

In Table 3 the evolution of the percentage of employees of age group 15-24 with a contract of limited duration (annual average) is shown for the period 2012-2016, in comparison with EU averages and values for two groups of EU countries - five countries with highest percentages and five other countries with lowest percentages. It is seen that this percentage for Macedonia varies significantly - between $22.2 \%$ and 26.2 \%). In comparison with more developed countries (such as Slovenia, Portugal and Spain), this value is low, but when comparing to Bulgaria $(12.7 \%$ in 2016) and Romania (3.0\% in 2016), it is rather high. Here small variations of percentages are observed for other countries except Croatia. The case of Croatia is particularly important. As is seen, at the beginning of the considered period the percentage was medium (41.8\% in 2012), while at the end of the considered period it attained a high value close to the percentages for Slovenia, Portugal and Spain $(61.7 \%$ in 2016). In this case, the transition from medium to high percentages can be attributed to the changes uniquely after the accession to EU. Thus, in the case of more developed EU countries high percentage of employees of age group 15-24 with a contract of limited duration can be connected to high mobility of the work force. In the case of Macedonia, mobility is rather limited and hence the percentages higher than in the countries with similar level of economic development can be interpreted as a measure of high job position insecurity. Therefore, it is to be concluded that in Macedonia position of young workers on the labour market is substantially more insecure than in the countries with similar level of economic development. In combination with the high unemployment, high risk of poverty and social exclusion, the relatively high level of employees with a contract of limited duration for young people aged 15-24, puts this group in a particularly 
difficult position on the labour market and in the society. Thus, it is required from the SESAME tools to provide enough detailed data concerning employment characteristics of the young people, in order to identify their position on the labour market, to elucidate the reasons for their unfavourable status, as well as the possibilities for its improvement.

In Table 4 full-time employment by economic activity is shown for the period 20122016, in comparison with EU-28 average, according NACE A 10 classification. It is seen that despite the high participation of contracts of limited duration, full time jobs are predominant. In almost all activities, percentage is higher than $95 \%$. Exceptions are present in activities where their nature of the activity itself limits the possibilities for full time work, such are the Agriculture, forestry and fishing; Arts, entertainment and recreation, and Real estate activities. Corresponding percentages for part-time employment by economic activity are shown in Table 5.

Table 4 Full-time employment by economic activity - NACE A10 (NACE Rev. 2), age from 15 to 64 years

\begin{tabular}{|c|c|c|c|c|c|c|}
\hline NACE_R2 & GEO/TIME & 2012 & 2013 & 2014 & 2015 & 2016 \\
\hline \multirow{2}{*}{ Total - all NACE activities } & EU (28) & 80.8 & 80.4 & 80.4 & 80.4 & 80.5 \\
\hline & Macedonia & 93.9 & 95.6 & 94.2 & 95.8 & 95.3 \\
\hline \multirow{2}{*}{ Agriculture, forestry and fishing } & EU (28) & 80.9 & 81.5 & 81.5 & 81.9 & 83.2 \\
\hline & Macedonia & 81.3 & 87.5 & 86.4 & 88.4 & 85.5 \\
\hline \multirow{2}{*}{ Industry (except construction) } & EU (28) & 93.0 & 92.8 & 92.9 & 93.0 & 92.9 \\
\hline & Macedonia & 98.4 & 98.7 & 98.6 & 98.7 & 98.8 \\
\hline \multirow{2}{*}{ Construction } & EU (28) & 92.8 & 92.3 & 92.5 & 92.6 & 92.6 \\
\hline & Macedonia & 93.9 & 97.0 & 92.5 & 94.4 & 95.4 \\
\hline \multirow{2}{*}{$\begin{array}{l}\text { Wholesale and retail trade, } \\
\text { transport, accommodation and } \\
\text { food service activities }\end{array}$} & EU (28) & 78.1 & 77.8 & 77.9 & 77.7 & 77.7 \\
\hline & Macedonia & 95.5 & 96.3 & 93.9 & 96.3 & 96.6 \\
\hline \multirow{2}{*}{ Information and communication } & EU (28) & 86.3 & 86.7 & 86.8 & 87.4 & 87.4 \\
\hline & Macedonia & 95.5 & 98.2 & 97.8 & 99.3 & 99.3 \\
\hline \multirow{2}{*}{ Financial and insurance activities } & EU (28) & 86.9 & 86.2 & 86.4 & 86.4 & 86.6 \\
\hline & Macedonia & 98.9 & 97.8 & 100.0 & 99.0 & 99.1 \\
\hline \multirow{2}{*}{ Real estate activities } & EU (28) & 80.2 & 79.8 & 80.8 & 80.6 & 80.7 \\
\hline & Macedonia & 100.0 & 77.8 & 77.8 & 84.6 & 93.8 \\
\hline \multirow{2}{*}{$\begin{array}{l}\text { Professional, scientific and } \\
\text { technical activities; administrative } \\
\text { and support service activities }\end{array}$} & EU (28) & 77.0 & 76.3 & 76.7 & 76.6 & 76.7 \\
\hline & Macedonia & 96.6 & 96.0 & 95.2 & 97.1 & 93.1 \\
\hline \multirow{2}{*}{$\begin{array}{l}\text { Public administration, defence, } \\
\text { education, human health and } \\
\text { social work activities }\end{array}$} & EU (28) & 75.5 & 75.0 & 74.9 & 74.9 & 74.8 \\
\hline & Macedonia & 97.5 & 98.3 & 98.5 & 98.6 & 98.4 \\
\hline \multirow{2}{*}{$\begin{array}{l}\text { Arts, entertainment and } \\
\text { recreation; other service activities; } \\
\text { activities of household and extra- } \\
\text { territorial organizations and bodies }\end{array}$} & EU (28) & 63.2 & 63.2 & 62.9 & 63.5 & 63.8 \\
\hline & Macedonia & 87.7 & 91.5 & 82.1 & 92.4 & 91.4 \\
\hline
\end{tabular}

Source: Eurostat, 2017, State Statistical Office, 2017.

As is seen in Table 5, highest percentage of part-time employment are in Agriculture, forestry and fishing (14.5\% in 2016); Arts, entertainment and recreation (8.6\% in 2016) and Real estate activities (19.3\% in 2016). For some of these activities, the percentages for EU-28 average are exceptionally high: in Arts, entertainment and recreation it is $36.2 \%$ in 2016 . It is to be noted that except for Professional, 
scientific and technical activities; administrative and support service activities, for all other activities the percentage is substantially decreasing with time. The increase of this percentage can be attributed to the increased offer of newly created part-time jobs of this kind. Contrary to the case of Macedonia, in EU the percentages are stable with the time.

Here, presented data show that in Macedonia both extent of the employees with a contract of limited duration and full time employment are higher than is to be expected. Above finding can be attributed to the exceptionally high unemployment rate and low salaries, pushing workers towards full time jobs, even if the contract is of limited duration.

Table 5 Part-time employment by economic activity - NACE A10 (NACE Rev. 2), age from 15 to 64 years

\begin{tabular}{|c|c|c|c|c|c|c|}
\hline NACE_R2 & GEO/TIME & 2012 & 2013 & 2014 & 2015 & 2016 \\
\hline \multirow{2}{*}{ Total - all NACE activities } & EU (28) & 19.2 & 19.6 & 19.6 & 19.6 & 19.5 \\
\hline & Macedonia & 6.1 & 4.4 & 5.8 & 4.2 & 4.7 \\
\hline \multirow{2}{*}{ Agriculture, forestry and fishing } & EU (28) & 19.1 & 18.5 & 18.5 & 18.1 & 16.8 \\
\hline & Macedonia & 18.7 & 12.5 & 13.6 & 11.6 & 14.5 \\
\hline \multirow{2}{*}{ Industry (except construction) } & EU (28) & 7.0 & 7.2 & 7.1 & 7.0 & 7.1 \\
\hline & Macedonia & 1.6 & 1.3 & 1.4 & 1.3 & 1.2 \\
\hline \multirow{2}{*}{ Construction } & EU (28) & 7.1 & 7.6 & 7.5 & 7.4 & 7.4 \\
\hline & Macedd & 6.1 & 2.8 & 7.5 & 5.8 & 4.4 \\
\hline \multirow{2}{*}{$\begin{array}{l}\text { Wholesale and retail trade, } \\
\text { transport, accommodation and } \\
\text { food service activities }\end{array}$} & EU (28) & 21.9 & 22.1 & 22.1 & 22.3 & 22.3 \\
\hline & Macedonia & 4.5 & 3.7 & 6.1 & 3.7 & 3.4 \\
\hline \multirow{2}{*}{ Information and communication } & EU (28) & 13.7 & 13.3 & 13.1 & 12.6 & 12.5 \\
\hline & Macedonia & 4.5 & & & & \\
\hline Financial and insurance activities & $\begin{array}{l}\text { EU (28) } \\
\text { Macedonia }\end{array}$ & 13.1 & 13.8 & 13.6 & 13.6 & 13.4 \\
\hline Real estate activities & $\begin{array}{l}\text { EU (28) } \\
\text { Macedonia }\end{array}$ & 19.8 & 20.1 & 19.2 & 19.4 & 19.3 \\
\hline \multirow{2}{*}{$\begin{array}{l}\text { Professional, scientific and } \\
\text { technical activities; administrative } \\
\text { and support service activities }\end{array}$} & EU (28) & 22.9 & 23.7 & 23.3 & 23.4 & 23.2 \\
\hline & Macedonia & 3.4 & 4.0 & 4.8 & 2.5 & 6.5 \\
\hline \multirow{2}{*}{$\begin{array}{l}\text { Public administration, defence, } \\
\text { education, human health and } \\
\text { social work activities }\end{array}$} & EU (28) & 24.5 & 25.0 & 25.1 & 25.1 & 25.2 \\
\hline & Maced & 2.4 & 1.6 & 1.5 & 1.4 & 1.7 \\
\hline \multirow{2}{*}{$\begin{array}{l}\text { Arts, entertainment and } \\
\text { recreation; other service } \\
\text { activities; activities of household } \\
\text { and extra-territorial organizations } \\
\text { and bodies }\end{array}$} & EU (28) & 36.8 & 36.8 & 37.0 & 36.5 & 36.2 \\
\hline & Macedonia & 12.3 & 8.5 & 17.9 & 7.6 & 8.6 \\
\hline
\end{tabular}

Note: not reliable.

Source: Eurostat, 2017, State Statistical Office, 2017.

From this particular analysis, we can conclude that the construction of an exhaustive SESAME module will provide a strong basis for the analysis of the socioeconomic specifics of the country and assist policy makers in adopting efficient strategies for resolving hard issues inhibiting faster socio-economic growth. Particular attention is to be paid to the position of young people on the labour market. 


\section{Conclusions}

Developing and implementing Social Accounting Matrix, accompanied by the SESAME approach will provide a solid basis for implementation of an integrated, economy-wide planning and modelling methodology that captures all segments and sectors of the national economy, within one integrated comprehensive framework. SESAME approach is capable to produce sets of data required to efficiently analyse the complicated situation of the workers on the labour market.

From the particular analysis of the SESAME for Macedonia the main research hypothesis has been confirmed. SESAME approach promise to be highly efficient in identifying the most sensitive issues connected to the high unemployment rate.

This methodology will significantly contribute to preparing and implementing scientifically and analytically based sustainable development strategic planning documents for obtaining higher economic development and growth potentials and economic welfare possibilities for the citizens of the Republic of Macedonia.

\section{References}

1. European Commission, International Monetary Fund, OECD, UN, World Bank (1993). System of National Accounts 1993. Brussels, Luxembourg, New York, Paris, Washington.

2. Eurostat (2017). Eurostat database. Available at http://ec.europa.eu/eurostat/data/database [31 October 2017].

3. Keuning, S. (1998). Interaction between national accounts and socio-economic policy. Review of Income and Wealth, Vol. 44, No. 3, pp. 345-359.

4. Keuning, S. (2000). Accounting for welfare in SESAME. Household Accounting Experience in Concepts and Compilation, Handbook of National Accounting, Studies in Methods, Series F, No. 75, Vol. 2, pp. 273-307.

5. Keuning, S., Timmerman, J. (1995). An information-system for economic, environmental and social statistics - integrating environmental data into the SESAME, NA-076. Statistics Netherlands, Voorburg.

6. Kjosev, S. (2012). Social Accounting Matrix - Methodological Basis for Sustainable Development Analysis. In Sustainable Development - Policy and Urban Development Tourism, Life Science, Management and Environment, Chaouki, G. (Ed.), InTech, Rijeka, pp. 269-284.

7. Kjosev, S., Gockov, G., Eftimov, Lj. (2014). Why is the Social Accounting Matrix Important for the Republic of Macedonia? The Young Economist Journal, Vol. 23, pp. 45-50.

8. Kjosev, S., Novkovska, B. (2017). Social Accounting Matrix - Methodological Basis for Sustainable Development Goals Analysis in the Western Balkan Countries. In Proceedings of the 14th International Symposium on Operational Research SOR'17, Zadnik Stirn, L., Kljajić Borštnar, M., Žerovnik, J., Drobne, S. (Eds.), Slovenian Society INFORMATIKA, Section for Operational Research, Bled, pp. 33-38.

9. Pyatt, G., Round, J. I. (Eds.) (1985). Social Accounting Matrices: A Basis for Planning. World Bank, Washington.

10. State Statistical Office (2017). Makstat data base. Available at http://makstat.stat.gov.mk/PXWeb/ [31 October 2017].

\section{About the authors}

Sasho Kjosev is Full Professor at Faculty of Economics, University "Ss. Cyril and Methodius" in Skopje, Republic of Macedonia, where he earned his PhD degree with the dissertation entitled "Application of the Social Accounting Matrix with special reference to the Republic of Macedonia". Since 2016, he has been serving as an Independent Member of the Supervisory Board of Stopanska Banka, AD Skopje, member of the National Bank of Greece (NBG) group. From 2014 to 2016, he was an independent, non-executive member of the 
Board of Directors at the Central Securities Depository AD Skopje. His professional career includes: Macedonian Academy of Sciences and Arts (1996-1998), World Bank in Skopje (1997-1998), the National Bank of Macedonia (1998) and the Faculty of Economics since September 1998. He participated in more than $30 \mathrm{EU}$, UNDP and World Bank funded projects in the country, including the preparation of the National Development Strategy and National Sustainable Development Strategy for Macedonia. He authored 7 books and more than scientific 60 articles. His professional interests include: macroeconomic (development) planning, development planning techniques, national accounting, sustainable development, regional and local economic development, labour economics and agricultural policy. Author can be contacted at: skosev@eccf.ukim.edu.mk.

Blagica Novkovska is an Assistant Professor in the Faculty of Economics at the University of Tourism and Management in Skopje. She offers more than 25 years of experience as statistician working with official statistics, from which 10 years as General Director of the State Statistical Office. She has performed many activities as international expert in statistics for IMF, World Bank, ILO, UNECE, EUROSTAT in different countries. She is elected member of the International Statistical Institute since 2011 and is also member of several national and international associations. She earned her PhD at the Faculty of Economics at the University "Ss. Cyril and Methodius" in Skopje following her dissertation entitled "Prevalence and measurement of hidden economy in the Republic of Macedonia". She leaded more than 10 national or multi-beneficiary EU funded projects in the field of official statistics. She coauthored in 4 books published by UN organizations and authored more than 40 research papers published in domestic and international journals and conference proceedings. Her professional interests include: macroeconomic modelling, clustering, quality management, sustainable development, regional development and labour economics. Author can be contacted at: b.novkovska@utms.edu.mk. 